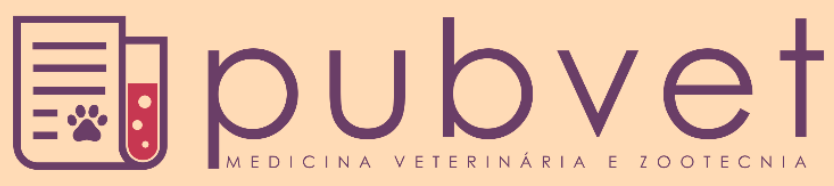

https://doi.org/10.31533/pubvet.v15n09a908.1-5

\title{
O ponto de vista da população sergipana quanto aos produtos apícolas
}

\author{
Rafaela Prado Gomes $^{1 \bullet}$, José Wislan Lima de Andrade ${ }^{2} \bullet$, Gladslene Góes Santos Frazão ${ }^{3 *}$ \\ ${ }^{l}$ Graduanda do curso de Medicina Veterinária da Associação de Ensino e Cultura Faculdade Pio Décimo; Aracaju, Sergipe, Brasil. \\ ${ }^{2}$ Médico Veterinário; Aracaju, Sergipe, Brasil. \\ ${ }^{3}$ Docente do curso de Medicina Veterinária da Associação de Ensino e Cultura Faculdade Pio Décimo; Aracaju, Sergipe, Brasil. \\ *Autor para correspondência, Email: gladsgoes@gmail.com
}

Resumo. Os produtos apícolas são mel, cera, própolis, geleia real, pólen e apitoxina. O Brasil é um dos maiores exportadores de mel de abelha, devido a grande variedade de flora e clima tropical. Para garantir a inocuidades dos produtos apícolas é necessário a presença de um responsável técnico no estabelecimento e na fiscalização do serviço de inspeção. $\mathrm{O}$ objetivo é conhecer o ponto de vista da população sobre os produtos apícolas no estado de Sergipe, e seu entendimento da importância de consumir um produto que passou por um serviço de inspeção, seus hábitos de consumo e onde ele é adquirido. A pesquisa foi realizada por meio de um aplicativo intitulado de Software Aplicativo Google Docs com a elaboração de perguntas e foi compartilhada majoritariamente por meio de aplicativos de mensagens e depois colhidas as informações para análise. Os resultados foram de 163 questionários respondidos por sergipanos, no qual a maioria diz conhecer sobre a importância de adquirir produtos apícolas que tem inspeção e o responsável técnico. $\mathrm{O}$ consumo de mel, segundo a maioria é baixo, mas consideram o sabor o mais atrativo apesar de os valores e o hábito hoje dificultarem o crescimento nas vendas. $\mathrm{O}$ produto mais consumido é o mel e o supermercado é o local onde as pessoas mais compram esses produtos.

Palavras-chave: Inspeção, mel, produtos apícolas, responsável técnico

\section{The point of view of sergipana population on apiculture products}

\begin{abstract}
The apiculture products are honey, wax, propolis, royal jelly, bee pollen and the apitoxin. The Brazil is one of the biggest exporters of honey in raison of the great variety of flora and the tropical weather. To ensure the harmlessness of the apiculture products is necessary the presence pf the Technician Manager in the establishment and the oversight of the inspection service. The aim is to know the point of view of the population on apiculture products in Sergipe state, and their knowing of the importance of consuming a product that passed on an inspection service, their consume habits and where it's acquired. The research was carried out through the application called Software Programs Google Docs with an elaboration of the questions and was shared mostly through messaging applications and then collected the information for analysis. The results were 163 questionnaires answered by sergipanos, in which mostly says knowing the importance of acquire apiculture products that has inspection and Technician Manager, even if the consumption according to the majority is low, consider the taste most attractive, although the value and habits today hinders sales growth, the product more consumed is honey and the supermarket the place where they buy its products.
\end{abstract}

Keywords: Inspection, honey, apiculture products, technician manager 


\section{Introdução}

O Brasil está em $8^{\circ}$ lugar no ranking de maiores exportadores de mel do mundo. Segundo o IBGE (2018), foram produzidas mais de 42,3 mil toneladas de mel. A região Sul é a maior produtora com 16,4 mil toneladas, seguida pelo Nordeste com 14,2 mil toneladas. Em 2018, no Brasil os valores das exportações do mel ultrapassaram 95,4 milhões de US\$ e foram exportadas 28,5 mil toneladas de mel (MDIC/MAPA, 2019). A importância do Brasil deve-se a sua grande variedade de flora e clima tropical. Os produtos oriundos desse sistema são mel, cera, própolis, geleia real, pólen e a apitoxina (EMBRAPA, 2007).

No Brasil, o consumo de mel está entre os menores do mundo. Em 2017, o consumo per capita foi próximo de $0,07 \mathrm{~kg} /$ pessoa/ano, diferente de alguns países como os Estados Unidos, principal destino do mel brasileiro que foi de $0,6 \mathrm{~kg} /$ pessoa/ano e países da Europa, que o consumo pode chegar a 1,5 $\mathrm{kg} /$ pessoa/ano (Vidal, 2019).

O responsável técnico tem por função garantir que o consumidor irá receber os produtos ou serviços de qualidade e com inocuidade, por meio da fiscalização dos estabelecimentos, treinamentos de colaboradores, notificação de irregularidades e de doenças. Os técnicos devem responder legalmente caso ocorra prejuízo ao cliente, seja por negligência, imperícia ou omissão. Dentro das áreas em que pode atuar se destacam a industrialização e a comercialização de carnes, o supermercado, a indústria de laticínios e a apicultura (CRMV-SE, 2006).

A expansão da produção apícola e o aumento do consumo destes produtos é um desafio enfrentado pelos apicultores.

O objetivo deste trabalho é conhecer o ponto de vista da população dos produtos apícolas no estado de Sergipe, sobre seu entendimento da importância de consumir um produto que passou por um serviço de inspeção, seus hábitos de consumo e onde ele é adquirido.

\section{Material e métodos}

A pesquisa foi realizada por meio de um aplicativo intitulado Software Aplicativo Google Docs sendo uma metodologia que objetiva simplificar a resolução do questionário, permitindo aos entrevistados responder, no momento que acharem mais conveniente. Com a formulação de três perguntas referentes à caracterização da população e nove perguntas de alternativas referentes ao ponto de vista da população quanto aos produtos apícolas. A pesquisa foi iniciada e compartilhada majoritariamente por meio de aplicativo de mensagens, sendo disponibilizado para o recebimento das respostas no dia 07/05/2020 até o dia 31/05/2020. Ao terminar a coleta, os dados foram organizados por questões e as respostas foram analisadas.

Das 191 pessoas que responderam a pesquisa, só foram analisadas as respostas das 163 pessoas do estado de Sergipe. De acordo com a Figura 1, 60\% dos entrevistados que responderam ao questionário eram do sexo feminino e $40 \%$ do masculino.

\section{Qual sexo você se define?}

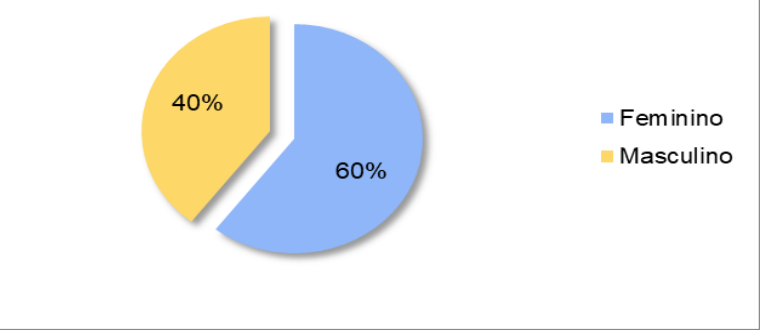

Figura 1. Sexo das pessoas entrevistadas sobre o conhecimento dos produtos apícolas no Sergipe.

Na Figura 2, é possível perceber que grande parte dos entrevistados são estudantes (50), seguido por médicos veterinários (8), advogados (7), autônomos, médicos e professores (6), funcionários públicos e 
recepcionistas (4), administradores, aposentados, bancários, desempregados e técnicos de enfermagens (3), contador, empresário, enfermeiro, militar, pedagogo, zootecnista (2), agricultor, ajustador, apicultor, assistente administrativo, auxiliar administrativo, auxiliar de educação e cultura, auxiliar de enfermagem, balconista, bacharel, biólogo, biomédico, bombeiro militar, caixa, comerciante, consultor de produção, consultor de vendas, corretor de imóveis, dentista, desenhista industrial, designer, digitador, empreendedor, engenheiro agrônomo, engenheiro civil, fiscal estadual agropecuário, fisioterapeuta, gerente, gestão de pessoas, gestora de recursos humanos, guarda municipal, industrial, jornalista, maquiador, marketing digital, policial, promotora de vendas, propagandista de indústria farmacêutica, psicólogo, publicitário, servidor público federal, técnico de alimentos, técnico de informática, tecnólogo em gestão e turismo, vendedora (1).

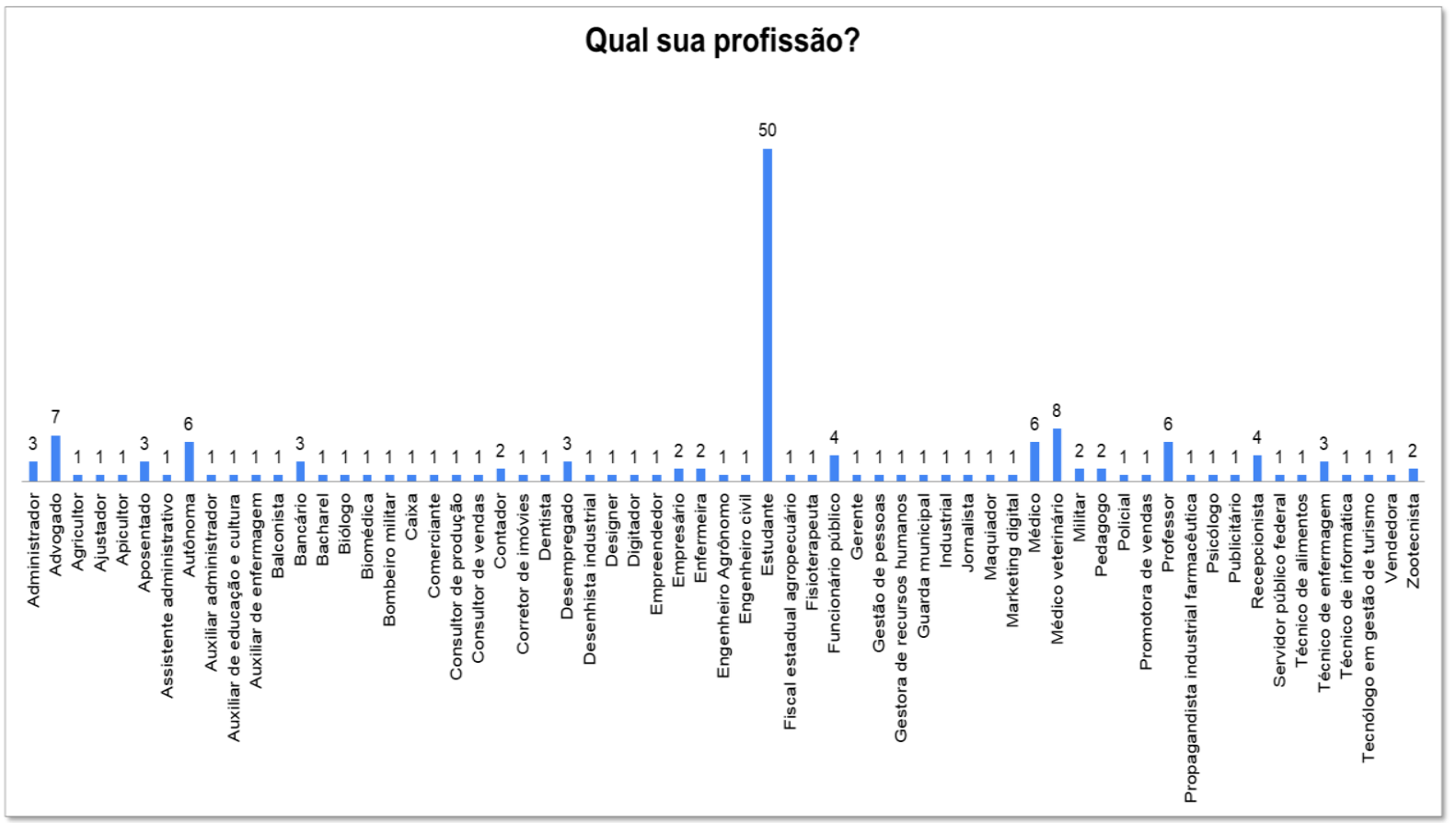

Figura 2. Profissão das pessoas entrevistadas sobre o conhecimento dos produtos apícolas no Sergipe

\section{Resultados e discussão}

O conhecimento da população sergipana sobre os produtos apícolas foi representado com base as nove perguntas respondidas por 163 entrevistados online.

Entre as pessoas entrevistadas mais do $90 \%$ tinham conhecimento sobre o serviço de inspeção, a importância de consumir produtos que passaram por um serviço de inspeção e a acuidade da presença do responsável técnico na indústria de alimentos (Figura 3 , Figura 4 e Figura 5). Sobre a possibilidade do produto que foi comprado passou pelo serviço de inspeção, $50 \%$ afirmaram possuir alta probabilidade, $30 \%$ mediana e $20 \%$ baixa (Figura 6 ).

Você sabe o que é o Serviço de Inspeção?

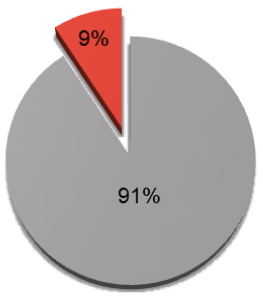

Figura 3. Conhecimento sobre o serviço de inspeção nos produtos apícolas por parte da população sergipana

= Não

\section{Você conhece a importância de consumir produtos que passaram por um Serviço de Inspeção?}

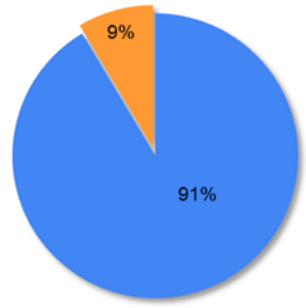

$=\operatorname{Sim}$

- Não

Figura 4. Conhecimento da importância de consumir produtos que passam pelo Serviço de Inspeção 


\section{Você sabe qual a importância de ter um Responsável Técnico na indústria de alimentos?}

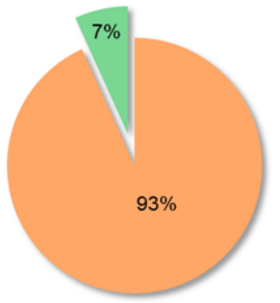

Figura 5. Conhecimento da importância do responsável técnico na indústria de alimentos

\section{Quando você compra um produto}

apícola, qual a probabilidade de consumir um produto que passou por um serviço de inspeção?

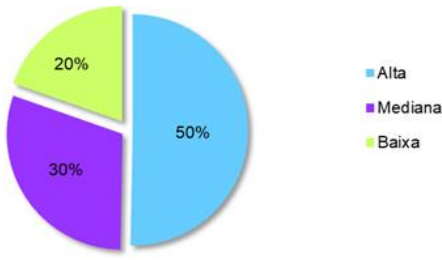

Figura 6. Probabilidade de comprar produtos apícolas com serviço de inspeção

A maioria dos entrevistados responderam consumir e comprar poucos produtos apícolas (52\% e 58\%, respectivamente), seguido por uma terça parte dos entrevistados que marcaram uma frequência razoável de consumo e compra. Em torno do $10 \%$ da população sergipana informaram consumir e comprar com frequência produtos apícolas. Por último podemos verificar que menos de 3\% da população sergipana não consomem ou nunca compraram produtos apícolas (Figura 7 e Figura 8).

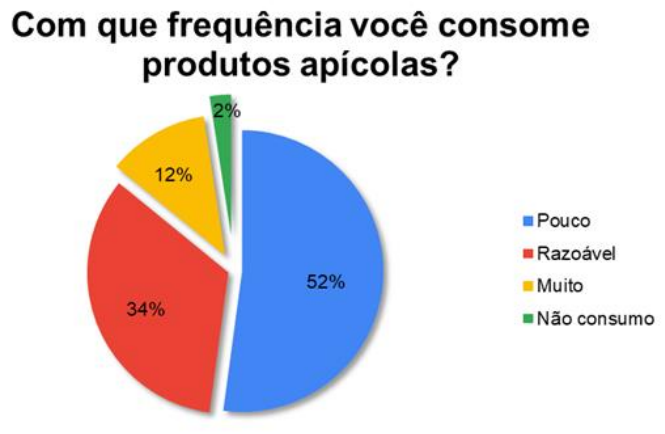

Figura 7. Frequência do consumo de produtos apícolas

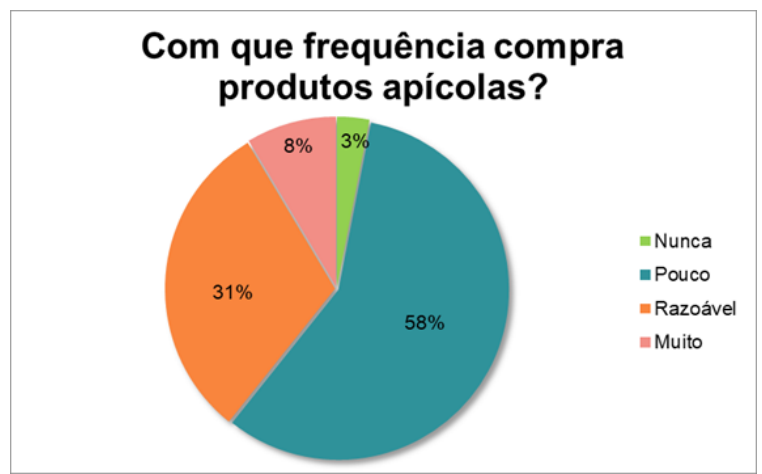

Figura 8. Frequência de compra de produtos apícolas

Conforme Figura 9, quando a questão foi o local de compra, 65 dos entrevistados responderam que adquirem os produtos em supermercados, $36 \mathrm{em}$ mercado, $21 \mathrm{em}$ mercearias, em apicultores, $6 \mathrm{em}$ farmácia, 5 em as lojas naturais, 3 em feiras ou terceiros, 2 em empórios e padarias e 1 em lojas de frios e vendedores locais. Isto indica que a maioria, $75 \%$ dos entrevistados adquirem os produtos nos estabelecimentos comerciais e poucas pessoas adquirem diretamente do apicultor (menos de $7 \%$ ). Segundo Silva (2007), no estudo realizado na Região Metropolitana da Grande Aracaju, a maior parte da população adquire os produtos em estabelecimentos comerciais (45\%), seguida da aquisição direta do produtor $(40 \%)$ e por último de vendedores ambulantes $(15 \%)$.

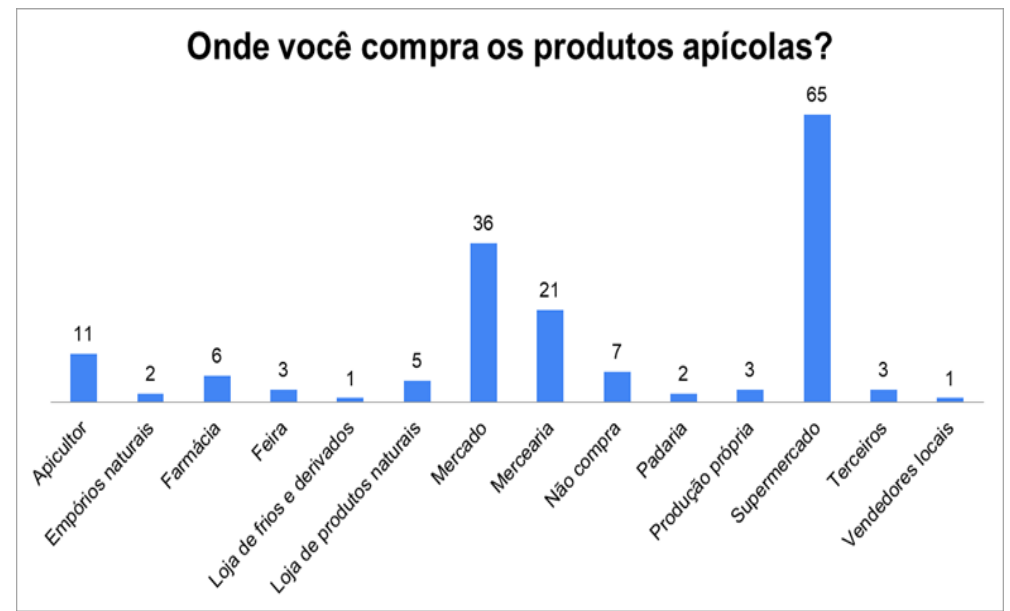

Figura 9. Forma de aquisição dos produtos apícolas no Sergipe 
De acordo com a figura 11, a maioria consome mais mel (88\%), depois a própolis (11\%), a cera e a geleia receberam a mesma quantidade de respostas $(0,5 \%)$ e o pólen não recebeu nenhuma $(0 \%)$.

$\mathrm{Na}$ figura 12 mostra que apenas $4 \%$ das respostas indicaram que o preço seria o maior motivo de degustar os produtos apícolas, em contraste aos $65 \%$ que afirmaram que seria o sabor. O aspecto mostra que $17 \%$ das pessoas e $14 \%$ dos votos foram para disponibilidade do produto.

\section{Qual o produto apícola que você mais consome?}

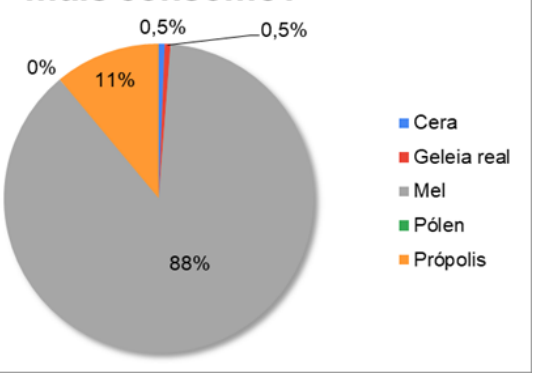

Figura 6. Produto apícola mais consumido pela população sergipana

\section{O que te motiva a degustar os produtos apícolas?}

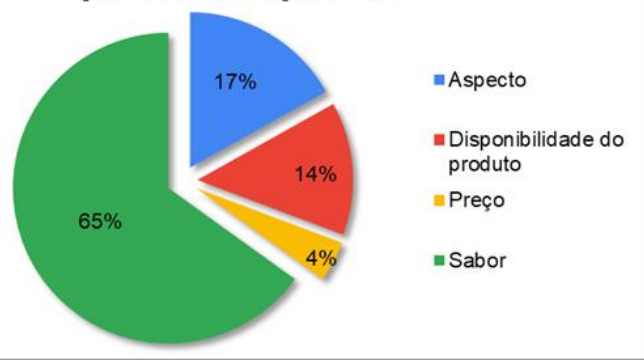

Figura 7. Motivos pelos que a população sergipana degusta produtos apícolas

De acordo com Silva (2007), a maioria afirmou que o preço é o maior motivo de não consumir mel (49\%), depois por quem respondeu não possuir o hábito (31\%), enquanto os que falaram não gostar ou ter outros motivos para não tiveram mesma quantidade de porcentagem (11\%).

\section{Conclusão}

Portanto, a maioria da população conhece a importância de adquirir produtos que possuem serviço de inspeção e presença de um responsável técnico, embora muitos não reconheçam, e afirmarem que possuem alta probabilidade de adquirirem a mercadoria que passou por um serviço de inspeção. $\mathrm{O}$ produto mais consumido é o mel, tendo o sabor e aspectos os principais motivos para o consumo, apesar de os valores e o hábito hoje dificulte o crescimento das vendas e o supermercado é o local onde mais compram esses produtos.

\section{Referências bibliográficas}

CRMV-SE. Manual de orientação e procedimentos para exercício de responsável técnico (RT). Aracaju, 2006.

EMBRAPA. ABC da Agricultura Familiar. Criação de abelhas: apicultura. Informação Tecnológica. Embrapa Meio-Norte. Brasília, DF. p.113, 2007.

Instituto Brasileiro de Geografia E Estatística - IBGE. Pesquisa pecuária municipal. IBGE (2017). https://sidra.ibge.gov.br/tabela/74

Ministério da Economia, Indústria, Comércio Exterior e Serviços. (2019) Comex Vis: Principais Produtos Exportados. http://www.mdic.gov.br/comercio-exterior/estatisticas-de-comercioexterior/comex-vis/frame-ppe?ppe $=1365$

Silva, E. G. Preferências da população da Região Metropolitana da Grande Aracaju (SE), sobre o consumo de produtos apícolas. 2007. 120f. Programa de Pós-Graduação - Universidade Federal do Mato Grosso do Sul, Aquidauana, 2007.

Vidal, M. F. Evolução na produção de mel na área de atuação do BNB. Caderno Setorial ETENE. Ano 4, n ${ }^{\circ} 62$, jan. 2019. https://www.bnb.gov.br/documents/80223/4570889/62 mel.pdf/ec4632d6-dc5e6aaa-6b89-52b179594ee1.

Histórico do artigo:

Recebido: 5 de abril de 2021 .

Aprovado: 1de junho de 2021.
Licenciamento: Este artigo é publicado na modalidade Acesso Aberto sob a licença Creative Commons Atribuição 4.0 (CC-BY 4.0), a qual permite uso irrestrito, distribuição, reprodução em qualquer meio, desde que o autor e a fonte sejam devidamente creditados. 